\title{
Vascular targeting of anti-CD40 antibodies and IL-2 into autochthonous tumors enhances immunotherapy in mice
}

\author{
Juliana Hamzah,, ${ }^{1}$ Delia Nelson, ${ }^{2}$ Gerd Moldenhauer, ${ }^{3}$ Bernd Arnold, ${ }^{3}$ \\ Günter J. Hämmerling, ${ }^{3}$ and Ruth Ganss ${ }^{1}$

\begin{abstract}
${ }^{1}$ Western Australian Institute for Medical Research, University of Western Australia Centre for Medical Research, Perth, Western Australia, Australia. ${ }^{2}$ School of Biomedical Sciences, Curtin University, Perth, Western Australia, Australia. ${ }^{3}$ Department of Molecular Immunology,

German Cancer Research Center, Heidelberg, Germany.
\end{abstract}

\begin{abstract}
Current anticancer therapy is a delicate balance between elimination of malignant cells and harmful side effects for the host. In this study, we used a tumor-homing peptide to engineer anti-CD40 agonist antibodies and recombinant IL-2 such that they were selectively delivered into spontaneously arising tumors in a transgenic mouse model of islet cell carcinogenesis. Intravenous injection of these agents, either separately or together, led to accumulation in the vicinity of tumor neovessels without toxic side effects. Although both molecules are critical for adaptive immunity, the most profound effects were seen in endothelial cells. Combined, local anti-CD40 and IL-2 therapy reduced tumor vascularity and significantly delayed tumor growth in mice. Remarkably, tumor-bearing mice remained disease-free long-term when targeted anti-CD40 and IL-2 were combined with transfers of preactivated antitumor immune cells. In this therapeutic setting, triggering of CD40 on endothelial cells induced an inflammatory response of the vessel wall and facilitated effector cell accumulation in the tumor parenchyma while IL-2 promoted antigen-specific immune cell persistence. We believe this is a novel and highly effective anticancer approach, whereby tumor stroma is "conditioned" for enhanced immune cell entry and survival, facilitating immune-mediated tumor destruction and leading to a sustained antitumor response.
\end{abstract}

\section{Introduction}

Much effort has been directed to develop reagents that target tumor- or stroma-specific antigens as a means of delivering bioactive molecules into deeply embedded tumors $(1,2)$. Selectively targeting tumor vascular endothelium is of particular interest since it is strikingly different to normal tissue vasculature (3). Joyce et al. have recently used in vivo phage display screening to identify peptides that specifically bind to tumor vasculature but not to normal pancreatic vessels in a transgenic mouse model of islet carcinogenesis (4). In these RIP-Tag mice, SV40 large T antigen (Tag) expression is controlled by the rat insulin gene promoter (RIP), which leads to stepwise formation of insulinomas through a well defined pathway (5). Here we use such a tumor-homing peptide (RGR peptide, CRGRRST) to specifically deliver potent immune stimulatory agents, agonistic CD40 antibody and IL-2, into inaccessible, spontaneously developing RIP-Tag tumors. Adjuvant CD40 antibody therapy has been reported to enhance antitumor immunization strategies (6-8) or promote tumor elimination as a single agent (9-11) in mouse models. These beneficial antitumor effects were mainly attributed to a crucial role of CD40 in the maturation of dendritic cells (DCs) and to substitute for $\mathrm{CD}^{+}$ help in priming cytotoxic T lymphocyte (CTL) responses (12-14). More recently, it has been reported that combining CD40-mediated CTL activation with immune-reactive cytokines such as IL-2 (15) results in greater antitumor responses than using single

Nonstandard abbreviations used: RIP, rat insulin gene promoter; Tag, SV40 large $T$ antigen.

Conflict of interest: The authors have declared that no conflict of interest exists. Citation for this article: J. Clin. Invest. 118:1691-1699 (2008). doi:10.1172/JCI33201. agents (16). Although clinically approved, systemic IL-2 in humans is associated with significant toxicity, limiting its application (17). Similarly, low-dose systemic anti-CD40 monoclonal antibodies have also been associated with toxic inflammatory syndromes in mice (11) and now humans (18).

In the present study, we aimed to provide proof of principle that tumors that are deeply embedded in the parenchyma, as many human cancers are, can be targeted via the blood circulation with reduced systemic toxicity. Moreover, we analyzed the impact of locally enriched anti-CD40/IL-2 treatment on progressive tumor growth and antitumor immunity. Finally, we translated our findings into a highly efficient combination therapy, which "preconditions" the tumor by targeting the stroma, thus enabling specific effector T cells to access and destroy the tumor.

\section{Results}

Peptide-mediated homing of immune stimulatory agents into solid tumors. RIP1-Tag5 transgenic mice develop angiogenic islets, some of which become vascularized tumors (insulinomas) by the age of 30 weeks $(19,20)$. RGR peptide (CRGRRST) homes into the aberrant vasculature of these angiogenic islets and tumors (4). We exploited these properties to focally deliver anti-CD40 antibodies and IL-2 directly into the tumors. RGR peptide was conjugated to anti-CD40 antibodies (FGK45) with a myc epitope linker (antiCD40-RGR). Successful coupling was demonstrated in a western blot using anti-myc antibodies (Figure 1A). In addition, a recombinant fusion protein of murine IL-2 and C-terminal RGR peptide (IL-2-RGR) was bacterially expressed and shown to be as bioactive as recombinant unconjugated human or murine IL-2 in stimulating IL-2-dependent T cell proliferation (Figure 1B). To test their 

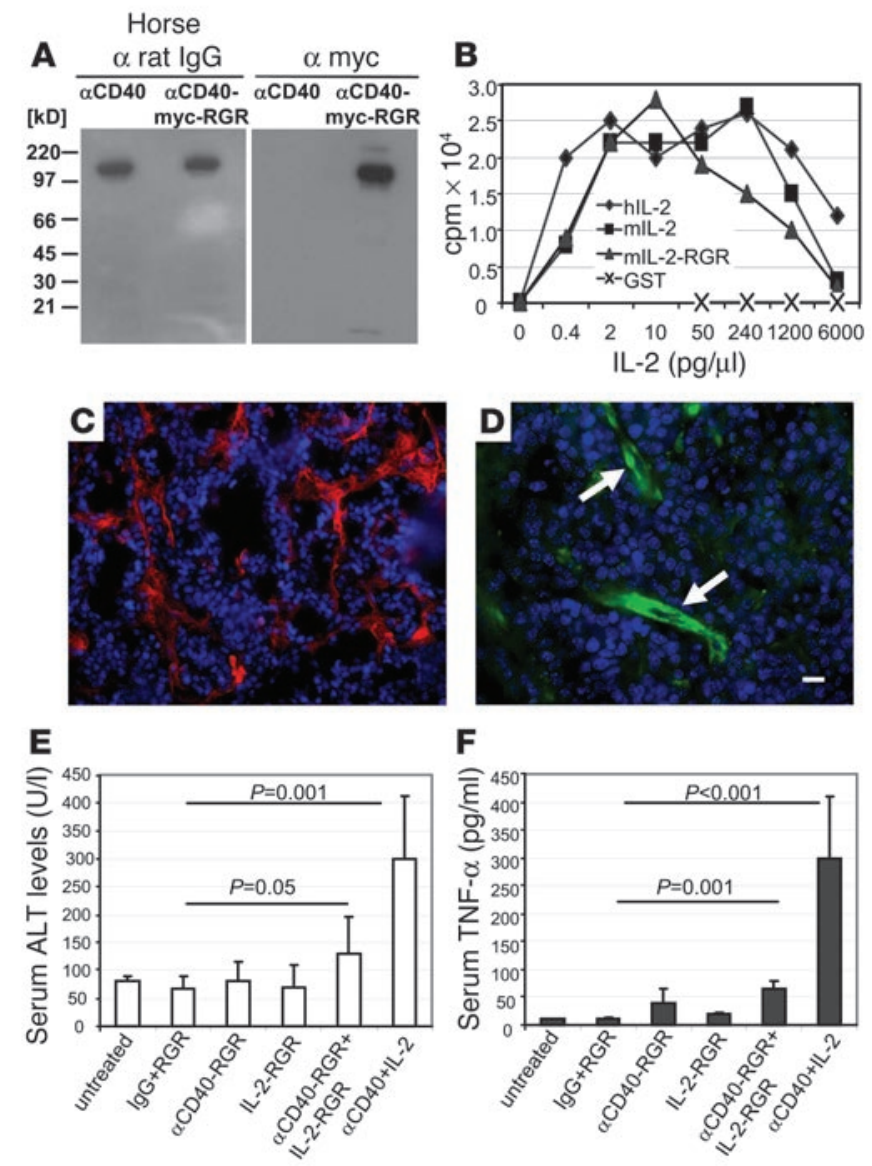

intratumoral homing capacity, both RGR-coupled agents were injected i.v. into 27-week-old, tumor-bearing RIP1-Tag5 mice and allowed to circulate for 5 minutes. Specific targeting of the compounds to the vicinity of tumor blood vessels was shown by immunohistochemistry (Figure 1, C and D). Liver, kidney, lung, or normal pancreatic tissue did not display immune reactivity (data not shown). This is consistent with studies by Joyce et al., which first demonstrated the exclusive binding capability of RGR-FITC molecules to angiogenic vessels in RIP-Tag tumors (4). Moreover, compared with unconjugated compounds, anti-CD40-RGR/IL-2RGR treatment induced limited liver toxicity, as assessed by serum alanine aminotransferase and serum TNF- $\alpha$ (Figure 1, E and F) (21) and reduced systemic immune responses (Supplemental Figure 1; supplemental material available online with this article; doi:10.1172/JCI33201DS1). Our data thus demonstrate that vascular targeting is a viable approach to deliver immune-modulating, and otherwise systemically toxic, agents into tumors, which are not accessible by direct intratumoral injections.

Combined intratumoral anti-CD40/IL-2 therapy reduces tumor vascularity. To assess the efficacy of intratumoral anti-CD40/IL-2 therapy, tumor-bearing 23-week-old RIP1-Tag5 mice (average tumor burden at 23 weeks, $53 \pm 43 \mathrm{~mm}^{3}$ ) were treated with anti-CD40-RGR and/ or IL-2-RGR over 10 weeks and survival was monitored (Figure 2A). Untreated RIP1-Tag5 mice succumb to insulinomas at the age of $28 \pm 3$ weeks due to overproduction of insulin and hypoglycaemia (Figure 2B; end-stage tumor burden at $28 \pm 3$ weeks, $120 \pm 52 \mathrm{~mm}^{3}$; "end-stage" is defined as decrease in blood glucose levels below 30

\section{Figure 1}

Delivery of RGR-fusion compounds into RIP1-Tag5 tumors. (A) AntiCD40 antibodies and RGR-conjugated antibodies were separated on a nonreducing SDS/PAGE. Antibodies were visualized with an anti-rat IgG antibody. Successful conjugation with myc-tagged RGR peptide was demonstrated by reprobing the membrane with anti-myc antibodies. (B) Proliferation of IL-2-dependent CTL.L2 T cells after incubation with serial dilutions of commercial recombinant human $(\mathrm{h}) \mathrm{IL}-2$, bacterially expressed murine (m) IL-2, IL-2-RGR fusion product, and GSTtag alone as control. (C) Accumulation of $100 \mu \mathrm{g}$ anti-CD40-RGR antibodies and (D) $100 \mu \mathrm{g} \mathrm{IL-2-RGR} \mathrm{in} \mathrm{RIP1-Tag5} \mathrm{tumors} 5$ minutes after i.v. injection. Arrows highlight immune reactivity on blood vessels. (E) Serum alanine aminotransferase (ALT) values and (F) serum TNF- $\alpha$ of different treatment groups analyzed after 2 weeks of treatment (Figure 2A). Controls are untreated 25-week-old RIP1-Tag5 mice and mice injected with rat IgG plus RGR peptide. Original magnification, $\times 20($ C); $\times 40$ (D). Scale bar: $50 \mu \mathrm{m}$ (C); $25 \mu \mathrm{m}$ (D).

$\mathrm{mg} / 100 \mathrm{ml}$ indicative of imminent death). Of note, long-term i.v. treatment with anti-CD40 antibodies (FGK45, unconjugated) combined with IL-2 (without RGR peptide) had some beneficial effects in $20 \%$ of treated mice. However, $40 \%-50 \%$ of treated mice died unexpectedly after 2-3 weeks of treatment indicative of systemic toxicity (Figure 2B). Tumor targeted IL-2-RGR treatment alone had no effect on the overall survival of transgenic mice (Figure 2C; end-stage tumor burden at $29 \pm 2$ weeks, $\left.110 \pm 46 \mathrm{~mm}^{3}\right)$. Intratumoral anti-CD40-RGR alone conferred a small but statistically significant survival advantage (Figure 2C; end-stage tumor burden at $31 \pm 2$ weeks, $\left.120 \pm 38 \mathrm{~mm}^{3} ; P=0.02\right)$. In contrast, a dramatic therapeutic effect was observed with anti-CD40-RGR/IL-2-RGR combination treatment. In this group, no premature death was recorded and $40 \%$ of treated mice survived up to 50 weeks before they succumbed to insulinomas (Figure 2C; end-stage tumor burden at 50 weeks, $\left.115 \pm 60 \mathrm{~mm}^{3} ; P<0.005\right)$.

To investigate the effects which promoted long-term survival in the anti-CD40-RGR/IL-2-RGR group, pancreata from 30-weekold mice (after 7 weeks of therapy) were harvested for histology $(n=5$ mice). Size-matched tumors from all treatment groups (50-70 $\mathrm{mm}^{3}$ ) were compared. In anti-CD40-RGR/IL-2-RGR-treated tumors, CD31 staining revealed significantly reduced vascularity (Figure 3A, left panel). This is in clear contrast to tumors from anti-CD40/IL-2 combination groups (Figure 3A, right panel). Tumor vascularity was quantified across all treatment groups and confirmed the significant, low vessel count after intratumoral anti-CD40/IL-2 treatment (Figure 3A; $P=0.005$ ). The dramatically reduced blood supply correlated with a strong increase in tumor hypoxia (Figure $3 \mathrm{~B} ; P=0.005$ ). Surprisingly, none of the treated tumors had any significant $\mathrm{T}$ cell (Figure $3 \mathrm{C}$, for $\mathrm{CD}^{+} \mathrm{T}$ cells) or $\mathrm{B}$ cell (data not shown) infiltrate and quantification of infiltrating $\mathrm{CD}^{+}$and $\mathrm{CD}^{+} \mathrm{T}$ cells did not reveal statistically significant differences between untreated RIP1-Tag5 tumors and treatment groups. These findings indicate a direct antivascular effect of combined anti-CD40-RGR/IL-2-RGR treatment but not anti-CD40-RGR or IL-2-RGR alone, which ultimately impairs tumor growth. To further test this hypothesis, anti-CD40-RGR/IL-2-RGR treatment was repeated in 23-week-old RIP1-Tag5 mice, which were depleted of $\mathrm{CD}^{+}$and $\mathrm{CD}^{+} \mathrm{T}$ cells for a period of 5 weeks (Figure $3 \mathrm{D}$ ). This treatment had no impact on progressive tumor growth in RIP1-Tag5 mice. Interestingly, control IgG-treated and -depletion groups responded equally well to intratumoral therapy (Figure 

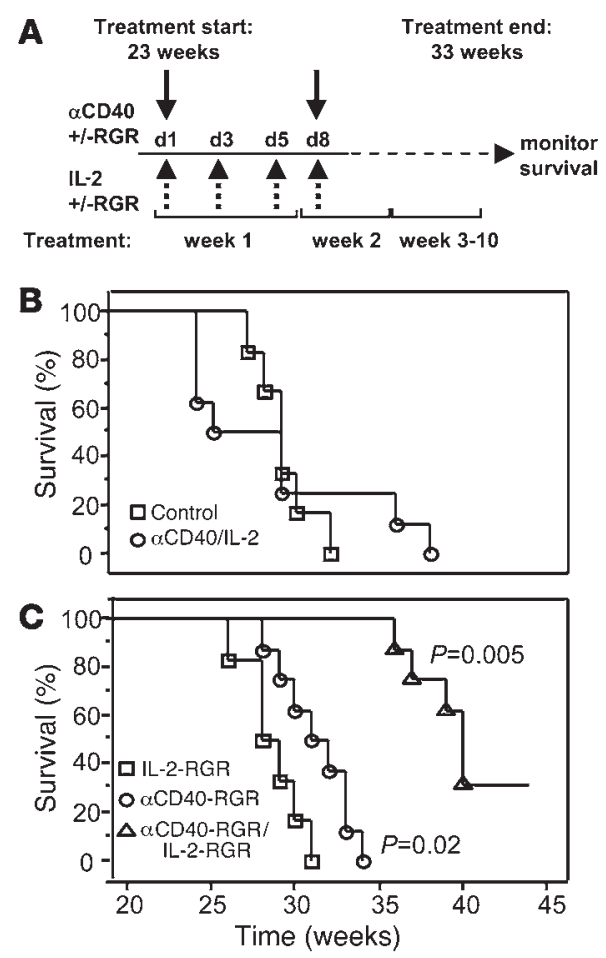

3E). The reduced vessel count in these groups (Figure 3F) further substantiates our finding that anti-CD40-RGR/IL-2-RGR therapy exerts major effects on the tumor stroma.

Intratumoral anti-CD40 therapy predominantly acts on tumor endothelium. The lack of immune cells in tumors and profound antiangiogenic effects after combined anti-CD40-RGR/IL-2-RGR treatment raises the question of which cell type intratumoral antiCD40 antibody targets. This is of particular interest since CD40 expression is not restricted to immune cells but also detected on nonhematopoietic stromal cells, like fibroblasts, vascular endothelium, and tumor cells (22-24), and thus, may exert pleiotropic effects on immune and tissue resident cells. We assessed CD40 expression in insulinomas of 27-week-old RIP1-Tag5 mice (Figure 4A) and, surprisingly, found expression exclusively on a majority of endothelial cells within the tumor bed. CD40 expression has been reported for a panel of normal endothelia in particular in lung and kidney $(23,25)$. However, by immunohistochemistry, vessels of normal pancreas had undetectable CD40 expression levels (Figure 4B), indicating a specific upregulation of CD40 on tumor vessels. Thus, endothelial cells are likely targets for intratumoral anti-CD40 therapy. This finding prompted us to establish CD40knockout RIP1-Tag5 bone marrow chimeras (CD40--- $\rightarrow$ RT5) where all bone marrow-derived cells lack the CD40 molecule, but the majority of tumor endothelial cells still express CD40 (Figure $4 C)$. In addition, crossing RIP1-Tag5 mice into a CD40-deficient background and providing wild-type $(\mathrm{C} 3 \mathrm{H})$ bone marrow creates chimeric mice $\left(\mathrm{C} 3 \mathrm{H} \rightarrow \mathrm{RT} 5 \times \mathrm{CD}_{40} 0^{-/-}\right)$with $\mathrm{CD} 40$-responsive immune cells, but most tumor vessels lack CD40 expression (Figure 4D). Tumorigenesis in chimeric RIP1-Tag $5 \times \mathrm{CD}_{40} 0^{--}$mice was unchanged as compared with wild-type RIP1-Tag5 mice (Figure 4E). Upon treatment with anti-CD40-RGR/IL-2-RGR combination therapy, only chimeric mice with $\mathrm{CD} 40^{+}$tumor vessels were responsive and survive long-term (Figure 4F; $P=0.004$ ). In con-

\section{Figure 2}

Therapeutic efficacy of intratumoral anti-CD40/IL-2 treatment. (A) Schematic representation of treatment regimen for 23-week-old RIP1Tag5 mice treated for 10 weeks. Survival was monitored up to 45 weeks. (B) Kaplan-Meier survival curve of RIP1-Tag5 mice treated with anti-rat IgG/RGR peptide as control and a combination of antiCD40 and IL-2 without RGR peptide. (C) Survival curve of RIP1-Tag5 mice treated with anti-CD40-RGR antibodies, IL-2-RGR fusion proteins, and a combination of anti-CD40-RGR/IL-2-RGR $(n=8-10)$. One out of 2 experiments is shown.

trast, treated $\mathrm{C} 3 \mathrm{H} \rightarrow \mathrm{RT} 5 \times \mathrm{CD} 40^{-/-}$mice only had a small survival advantage over untreated $\mathrm{C} 3 \mathrm{H} \rightarrow \mathrm{RT} 5 \times \mathrm{CD}_{40} 0^{-/-}$mice (Figure 3E; $P=0.03, P$ values compared to corresponding controls in Figure $4 \mathrm{E})$. These data demonstrate a critical role of tumor endothelia as direct targets for intratumoral anti-CD40 therapy.

Combined intratumoral targeting of anti-CD40 antibodies and IL-2 dramatically improves adoptive immunotherapy. RIP1-Tag5 mice are not tolerant toward the model tumor antigen Tag (26), and anti-CD40RGR/IL-2-RGR combination therapy elicited a transient increase in immune cell infiltration during the first 2 weeks of treatment (data not shown). However, this spontaneous infiltration was resolved by week 30 . Thus, we hypothesized that by providing ex vivo activated antitumor effector cells therapeutic efficacy might be substantially improved. Tumor-bearing RIP1-Tag5 mice were treated as indicate in Figure 2A, with adoptive transfers of antiTag $\mathrm{CD}^{+}$and $\mathrm{CD}^{+} \mathrm{T}$ cells (from TCR mice; refs. 27, 28) every 3 weeks. Regular adoptive transfers of activated $\mathrm{CD} 4^{+}$and $\mathrm{CD}^{+} \mathrm{T}$ cells did not significantly prolong survival in tumor-bearing RIP1Tag5 mice (29 \pm 3 weeks) (19), which was also comparable to treatment with IL-2-RGR and adoptive transfers (31 \pm 2 weeks). Intratumoral anti-CD40-RGR and adoptive transfers produced a better survival outcome ( $37 \pm 4$ weeks; $P=0.0001)$. Importantly, $80 \%$ of mice treated with the triple combination of intratumoral antiCD40-RGR/IL-2-RGR and adoptive transfers survived long-term (Figure 5A; $P<0.0001$ ). Upon termination at week 45, all surviving mice had normal pancreata without macroscopic tumor nodules. Interestingly, the tumor-selective destruction did not lead to a total loss of $\beta$ cells and consequent diabetes, possibly due to selective downregulation of Tag expression (Supplemental Figure 2). Eight long-term survivors of the triple treatment were monitored beyond week 45 and survived for more than 90 weeks. New tumors arose after a lengthy period without treatment due to continuos oncogene expression in pancreatic $\beta$ cells.

Furthermore, tumor specificity is required for immune-mediated destruction since concanavalin A-activated (ConA-activated), unspecific $\mathrm{T}$ cells did not enhance the previously observed survival benefits of combined anti-CD40-RGR/IL-2-RGR therapy (Figure $5 B)$. Surprisingly, therapeutic success of the triple treatment (antiCD40-RGR/IL-2-RGR, adoptive transfers) was mirrored in RIP1Tag5 mice reconstituted with bone marrow from $\mathrm{CD} 40^{-/-}$mice but failed in $\mathrm{C} 3 \mathrm{H} \rightarrow \mathrm{RT} 5 \times \mathrm{CD}_{40} /-$ chimeric mice (Figure $5 \mathrm{C}$ ). Again, this finding implies an important role of CD40-expressing tumor vessels in mediating the beneficial effects of the triple therapy. We therefore monitored changes in the vascular compartment after 3 consecutive anti-CD40-RGR injections at the time when the first activated anti-Tag effector cells were injected (age 26 weeks). Remarkably, tumor-targeted anti-CD40 therapy dramatically upregulated endothelial expression of ICAM, VCAM, and E-selectin (Figure 5D). This upregulation is not observed in IgG- or RGR 
A $\alpha$ CD40-RGR/L-2-RGR

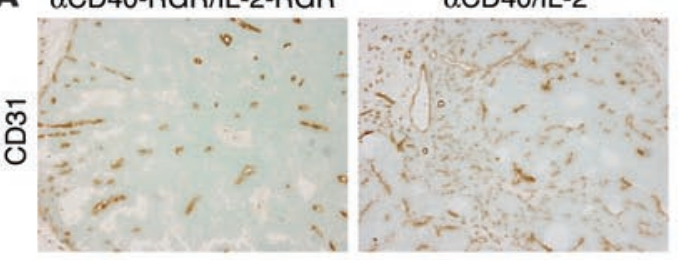

B

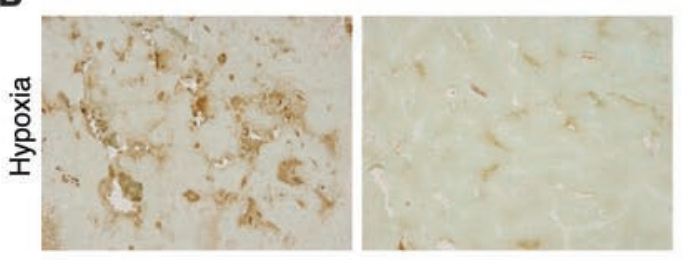

C

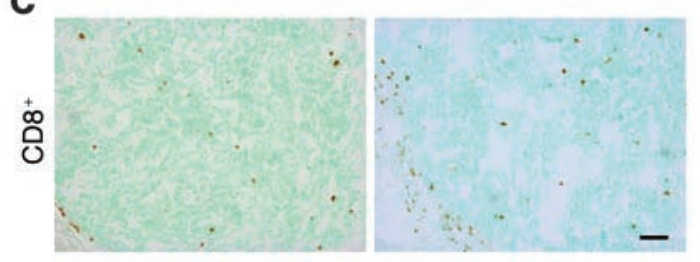

D

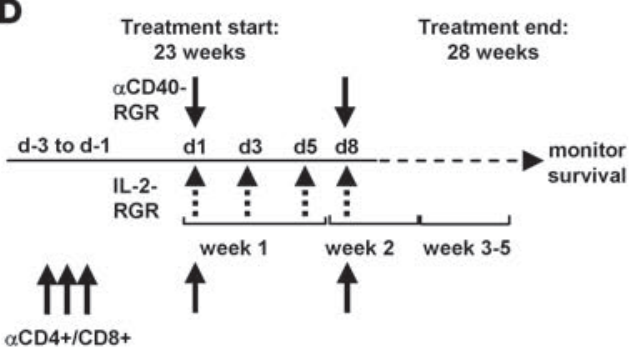

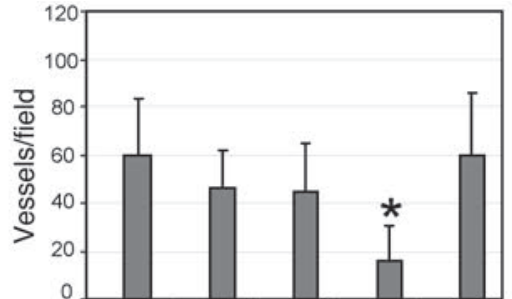
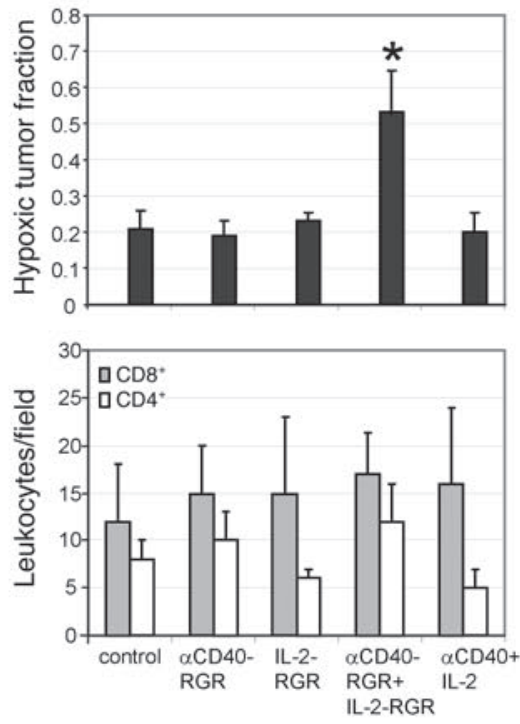

E

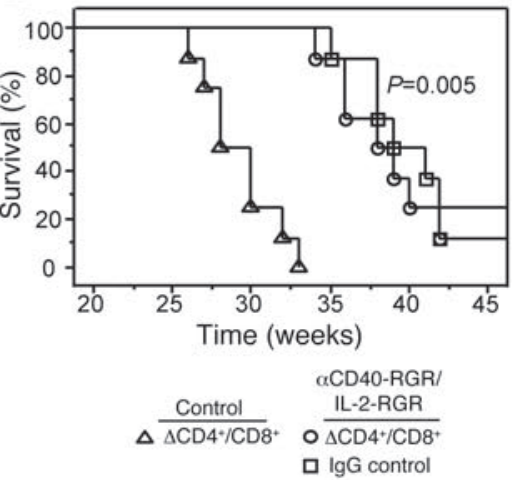

$\mathbf{F}$

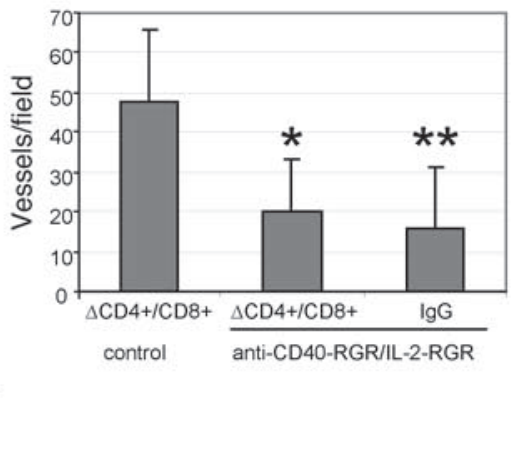

Figure 3

Intratumoral anti-CD40/IL-2 treatment reduces tumor vascularity. (A) Representative anti-CD31 vessel staining in 30-week-old RIP1-Tag5 tumors in anti-CD40-RGR/IL-2-RGR (left panel) or anti-CD40/IL-2 (right panel) treatment groups after 7 weeks of treatment and vessel counts. Vessel density was quantified by counting the number of CD31+ vessels within randomly selected fields $\left(n=5\right.$ mice; 5 fields per tumor; ${ }^{*} P=0.005$ compared with control mice treated with IgG/RGR peptide). (B) Corresponding hypoxia stain (hypoxyprobe-1 kit; Chemicon) and quantification of hypoxic tumor areas in different treatment groups $\left(n=5\right.$; ${ }^{*} P=0.005$ compared with control mice). (C) CD8 ${ }^{+}$T cells in anti-CD40-RGR/IL-2-RGR (left panel) or anti-CD40/IL-2 (right panel) treated tumors and quantification of CD8 ${ }^{+}$and CD4+ T cell infiltrates $(n=5$; no statistically significant difference was observed between treatment groups). (D) Schematic representation of treatment with anti-CD4+ and anti-CD8 ${ }^{+}$depletion for a period of 5 weeks. (E) Survival analysis of anti-CD4+ and anti-CD8 ${ }^{+}$depleted RIP1-Tag5 mice (control) and RIP1-Tag5 mice treated with antiCD40-RGR/IL-2-RGR combination therapy and depleting antibodies or IgG control $(n=8 ; P=0.005)$. (F) Quantification of vessel density in depletion groups ( $n=3$ mice; 5 fields per tumor; ${ }^{*} P=0.005$, ${ }^{\star \star} P=0.005$ compared with $\mathrm{CD}^{+} / \mathrm{CD} 8^{+}$depleted control mice). Original magnification, $\times 10(\mathbf{A}) ; \times 20$ (B and C). Scale bar: $100 \mu \mathrm{m}(\mathbf{A}) ; 50 \mu \mathrm{m}$ (B and C).

peptide-treated control insulinomas (Figure 5D) or in exocrine pancreatic tissue, liver, lung, and kidney (data not shown).

Intratumoral anti-CD40/IL-2 enhances immune effector cell accumulation in tumors. Activation of tumor endothelia after anti-CD40 treatment may enhance effector cell entry into the tumor. To test this, tumors from different treatment groups were harvested 7 days after the first adoptive transfers (Figure 2A; age 27 weeks) and analyzed by histology. Remarkably, an increased $\mathrm{T}$ cell infiltration was documented when preactivated, Tag-specific T cells were adoptively transferred into anti-CD40-RGR-treated RIP1Tag 5 mice. An even more dramatic accumulation of anti-Tag T cells into tumors was observed when anti-CD40-RGR was com- bined with IL-2-RGR, followed by adoptive transfer. In contrast, IL-2-RGR preconditioning alone had no effect on endothelial activation (data not shown) or lymphocytes in the tumor (Figure 6A). Nevertheless, IL-2 is highly beneficial during therapy. To further analyze the role of intratumoral IL-2, anti-Tag CD8 ${ }^{+}$ $T$ cell survival was monitored by their isolation from lymph nodes and tumors at different time points after transfer (Figure 6B). Preactivated anti-Tag $\mathrm{T}$ cells specifically homed into tumor-draining pancreatic lymph nodes where they proliferated, reaching a peak at day 7 after transfer; without further manipulation, these activated $\mathrm{T}$ cells do not accumulate in the tumor (29). Intratumoral IL-2 only extended the survival of T cells in lymph nodes. 


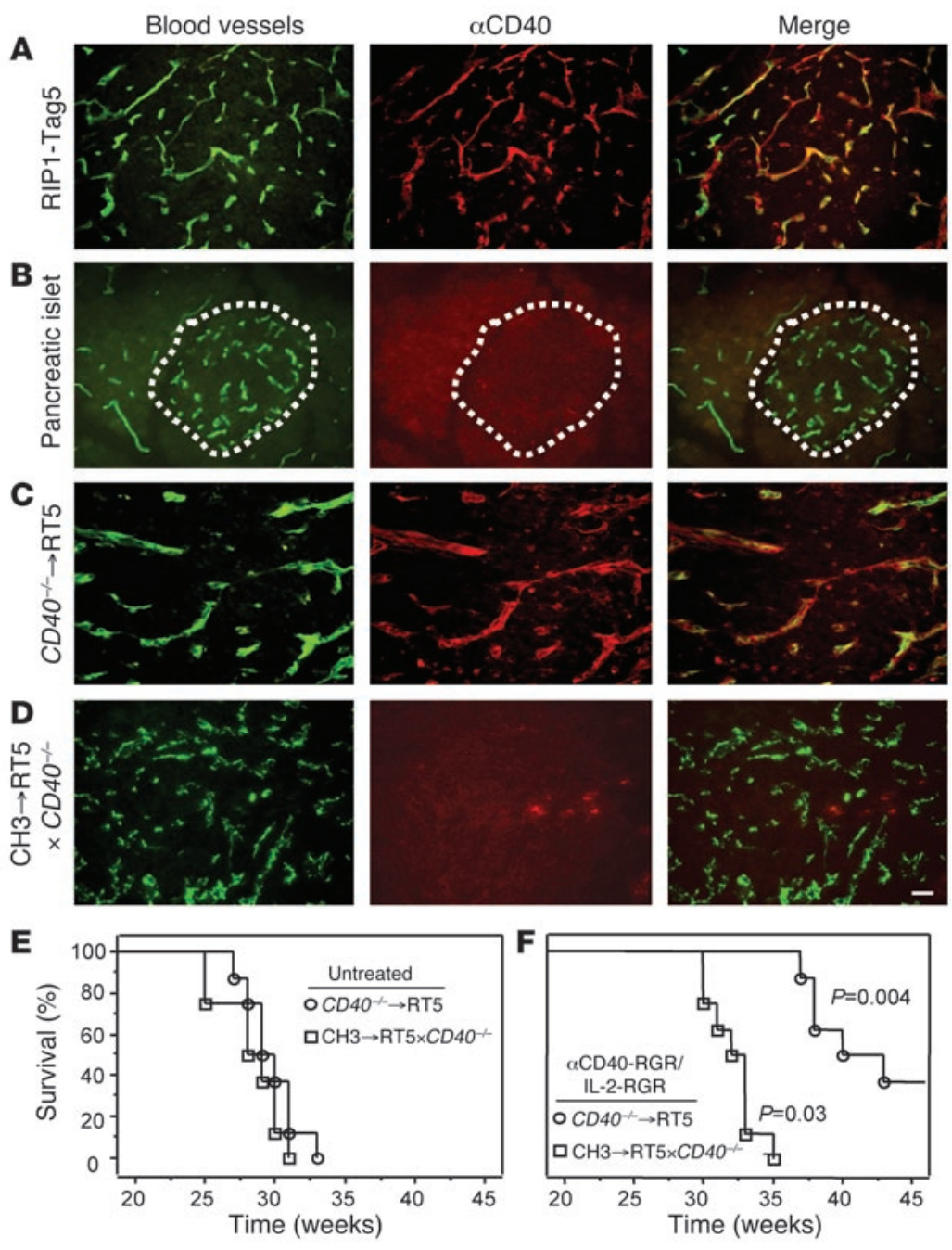

\section{Figure 4}

CD40 expression on tumor blood vessels. (A) To display blood vessels, 27-week-old RIP1-Tag5 mice were i.v. injected with FITC-labelled tomato lectin. Tumors were harvested and stained with anti-CD40 antibodies. Equally strong CD40 signals were visible in tumor nodules of different sizes analyzed in RIP1-Tag5 mice at 23, 25 , and 30 weeks of age (data not shown). (B) CD40 expression is not detectable by immunohistochemistry in normal pancreatic tissue. Dotted lines delineate islet of Langerhans. (C) CD40 expression on lectin-perfused tumor vessels from 27 -week-old $\mathrm{CD} 40^{-/-} \rightarrow \mathrm{RIP} 1$-Tag5 $\left(\mathrm{CD} 40^{-1-} \rightarrow \mathrm{RT5}\right)$ mice and (D) absence of CD40 expression on the vasculature of 27 -week-old $\mathrm{C} 3 \mathrm{H} \rightarrow \mathrm{RIP} 1$ Tag5 $\times C D 40^{-/-}$mice displayed after anti-CD31 and antiCD40 staining. Original magnification, $\times 40$. Scale bar: 25 $\mu \mathrm{m}$. (E) Survival analyses of chimeric RIP1-Tag5 mice and (F) chimeric RIP1-Tag5 mice after anti-CD40-RGR/ IL-2-RGR combination treatment $(n=8 ; P=0.004$ and $P=0.03$ compared with chimeric untreated controls).

improved immunotherapeutic outcome against a highly inaccessible, autochthonous murine tumor.

Intratumoral targeting for anticancer therapy. Our previous studies in RIP1-Tag5 mice have clearly demonstrated that even in the presence of a potent tumor antigen (Tag), immunotherapy fails because effector cell penetration and/or function within tumors are limited $(19,29,30)$. These limitations are reflected in the general lack of success when applied to cancer patients, even though generation of tumor-specific CTLs is often reported (31). However, manipulating the tumor to enhance permissiveness while avoiding toxicities of systemically delivered immune-stimulating reagents remains a major challenge. The logical alternative approach is to target these agents directly into the tumor bed. A unique and highly specific way to deliver therapies

In contrast, anti-CD40-RGR antibody enhanced extravasation of adoptively transferred $T$ cells, which transiently accumulated in the tumor, although the majority of T cells remained in the pancreatic lymph nodes; their survival was not extended in either site. Only when anti-CD40-RGR was combined with IL-2-RGR did the majority of adoptively transferred $\mathrm{T}$ cells locate into the tumor, and their survival was prolonged up to 28 days. These data imply a critical role for intratumoral anti-CD40 in $\mathrm{T}$ cell penetration, most likely through activation of angiogenic vessels. Once effector cells accumulate in the tumor, IL-2 promotes $\mathrm{T}$ cell persistence. Thus, anti-CD40 and IL-2 combination therapy acts in concert to substantially enhance intratumoral infiltration by adoptively transferred effector cells, which in turn leads to destruction of established tumors.

\section{Discussion}

In the present work, we have engineered clinically approved, currently used drugs for highly specific, targeted intratumoral delivery. Accumulation of anti-CD40 and IL-2 within the tumor environment had surprising effects on the newly formed vasculature and showed synergistic antitumor efficacy. Moreover, intratumoral anti-CD40/IL-2 therapy potentiated immune effector cell accumulation and persistence in the tumor, resulting in a dramatically into inaccessible, autochthonous tumors in mice and humans is to exploit the abnormal features of the tumor environment itself. Although this approach is in its infancy, there is accumulating evidence that each tumor bed has a specific "address" that can be targeted $(4,32,33)$. Here, we used the RGR peptide, which specifically homes to neoplastic vessels in the pancreas of RIPTag mice. The RGR peptide has homology to PDGF-B and is a putative ligand for PDFGR $\beta$. In RIP-Tag tumors, RGR colocalizes with endothelial cells and pericytes, a supportive vascular cell type surrounding endothelial cells (4). This peptide was used as a vehicle to target agonistic CD40 antibodies and/or recombinant IL-2 into highly angiogenic, aggressively growing islet cell carcinomas. These 2 agents were selected because of their documented immune-enhancing and potential vascular effects $(15,34)$, both essential criteria for therapeutic efficacy in RIP1-Tag5 mice (31).

Antitumor effects of agonistic CD40 antibodies have been extensively studied in a variety of mouse models with a major focus on their immune-enhancing properties $(6-9,11)$. Although CD40 agonist antibodies are in current clinical trials, recent publications raise concerns that systemic stimulation of CD40 may have pleiotropic and undesired effects. For instance, the induction of cytokine release syndrome $(11,18)$ may relate to a CD40-induced inflammatory reaction in the vessel wall of normal organs (34). 


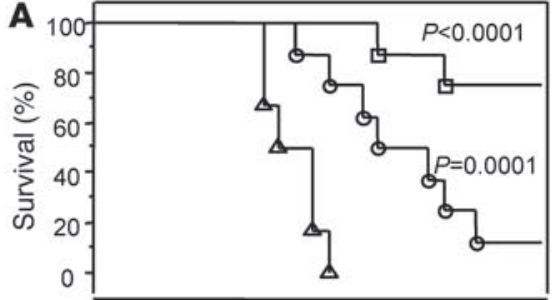

O CD40-RGR + T

$\triangle \mathrm{IL}-2-\mathrm{RGR}+\mathrm{T}$

$\alpha \mathrm{CD} 4-\mathrm{RGR} / \mathrm{IL}-2-\mathrm{RGR}+\mathrm{T}$
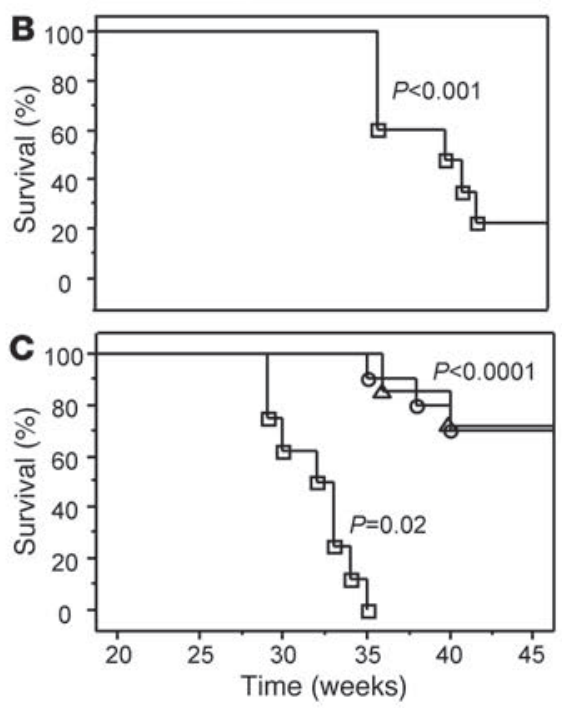

$\alpha \mathrm{CD} 40-\mathrm{RGR} / \mathrm{LL}-2-\mathrm{RGR}+\mathrm{T}$

\section{O $\mathrm{CD} 40^{\star} \rightarrow \mathrm{RT} 5$}

$\triangle \mathrm{CH} 3 \rightarrow \mathrm{RT} 5$

ㅁ $\mathrm{CH} 3 \rightarrow \mathrm{RT} 5 \times \mathrm{CD}_{4} 0^{-1}$

口 CD40-RGR/LL-2-RGR + ConA T

D ICAM
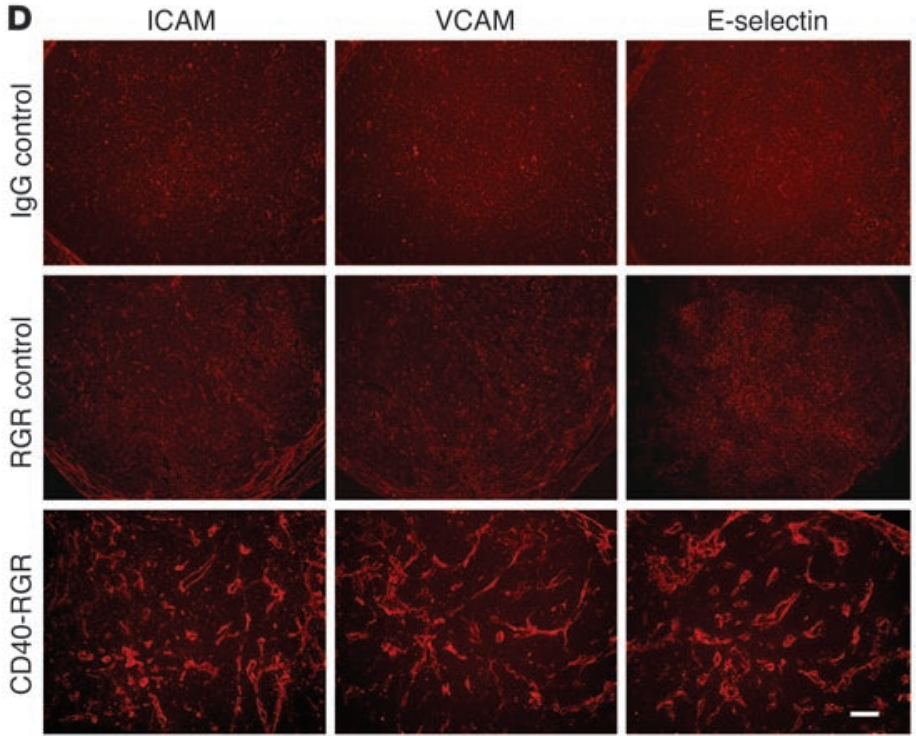

\section{Figure 5}

Adoptive T cell therapy in the presence of intratumoral inflammation. (A) Survival analyses of RIP1-Tag5 mice treated with IL-2-RGR, anti-CD40-RGR, and anti-CD40-RGR/IL-2-RGR in combination with adoptive transfers of preactivated $\mathrm{CD} 4^{+}$and CD8 ${ }^{+}$Tag-specific T cells $(T)$ ( $P$ values compared with IgG/RGR treated controls; Figure 2B). (B) Survival of RIP1-Tag5 mice treated with anti-CD40-RGR/IL-2-RGR and ConA activated lymphocytes from C3H mice (ConA T). (C) Kaplan-Meier analyses of chimeric RIP1-Tag5 mice receiving bone marrow from CD40 knockout $\left(\mathrm{CD} 40^{-/-} \rightarrow \mathrm{RT} 5\right)$ or wild-type $(\mathrm{C} 3 \mathrm{H} \rightarrow \mathrm{RT} 5)$ mice and RIP1-Tag5 $\times \mathrm{CD} 40^{-/-}$receiving bone marrow from wild-type mice $\left(\mathrm{C} 3 \mathrm{H} \rightarrow \mathrm{RT} 5 \times \mathrm{CD} 0^{--}\right)$, all treated with triple treatment (IL-2RGR, anti-CD40-RGR, adoptive transfers of Tag-specific T cells) ( $n=8-10$ for all survival studies; $P$ values compared with chimeric controls; Figure 4E). One of 2 experiments is shown. (D) RIP1-Tag5 mice at an age of 23 weeks were treated with 3 weekly injections of anti-CD40-RGR antibodies, IgG, or RGRpeptide. Tumors from control mice treated with IgG (upper panels) or RGR peptide alone (middle panels) do not show reactivity for ICAM, VCAM, or E-selectin. Anti-CD40-RGR treated RIP1Tag5 mice show upregulation of ICAM, VCAM, and E-selectin on tumor vessels (lower panel). Original magnification, $\times 10$. Scale bar: $100 \mu \mathrm{m}$.

demonstrates that local therapy is distinctively different to systemic drug delivery. To date, the beneficial effects of systemic anti-CD40/IL-2 administration have been entirely attributed to their immune-enhancing properties, in particular, activation of DCs by anti-CD40 and improved proliferation of $\mathrm{CD}^{+} \mathrm{T}$ cells by IL-2 $(16,36)$. Local enrichment of anti-CD40 and IL-2 in the tumor over at least 5 weeks led to a drastic reduction in tumor vessels, increase in hypoxia, and delay in tumor growth. Strikingly, this effect was only observed in combination therapy. While we have strong evidence that anti-CD40 acts through CD40 expressed on tumor vessels, the role of IL-2 is less well defined. There is evidence that IL-2 causes vascular leak syndrome through direct binding and damaging of endothelial cells (37). Alternatively, intratumoral IL-2 has been shown to decrease tumor vascularity via activated $\mathrm{CD}^{+}$effector cells, which may secret IFN- $\gamma$, a molecule with demonstrated antivascular effects $(15,38,39)$. However, the absence of a marked $\mathrm{T}$ cell infiltrate in end-stage tumors and our $\mathrm{T}$ cell depletion studies argue for direct toxic effects of IL-2 on tumor vessels in anti-CD40-treated RIP1-Tag5 mice.

In light of the controversy of pro- or antiangiogenic effects of anti-CD40 (40), it is important to note that although antiCD40 monotherapy had little impact on the overall survival of tumor-bearing RIP1-Tag5 mice, our findings do not supFurthermore, although systemic CD40 antibody in combination with IL-2 therapy has been reported to generate a strong initial antitumor immune response, the same regimen impairs memory response, leading to an inability to maintain a durable antitumor immunity (35). These recently documented, profound adverse effects of systemic anti-CD40/IL-2 treatment, together with our own findings in RIP1-Tag5 mice (Figure 2B), strongly support the need for targeted delivery into the tumor microenvironment.

Effectiveness of targeted anti-CD40/IL-2 therapy. We report here that sustained local anti-CD40/IL-2 therapy exerts major effects on tumor blood vessels. We believe this is a novel finding that port a proangiogenic role of CD40. This is of particular interest since a recent report has implicated CD40-CD40L interactions in the promotion of angiogenesis during mammary carcinogenesis in a transgenic BALB/NeuT tumor model (25). In the absence of CD40 or by depleting platelets as the source of stimulating CD40L, BALB/NeuT tumors develop slower and lack large vessels. In that analysis, tumors are deprived of CD40 stimulation early during carcinogenesis. In contrast, anti-CD40 therapy as conducted here acts on a well-established, highly angiogenic vasculature in latestage tumors. This suggests that CD40-CD40L interactions have a different impact on tumor angiogenesis depending on the phase 

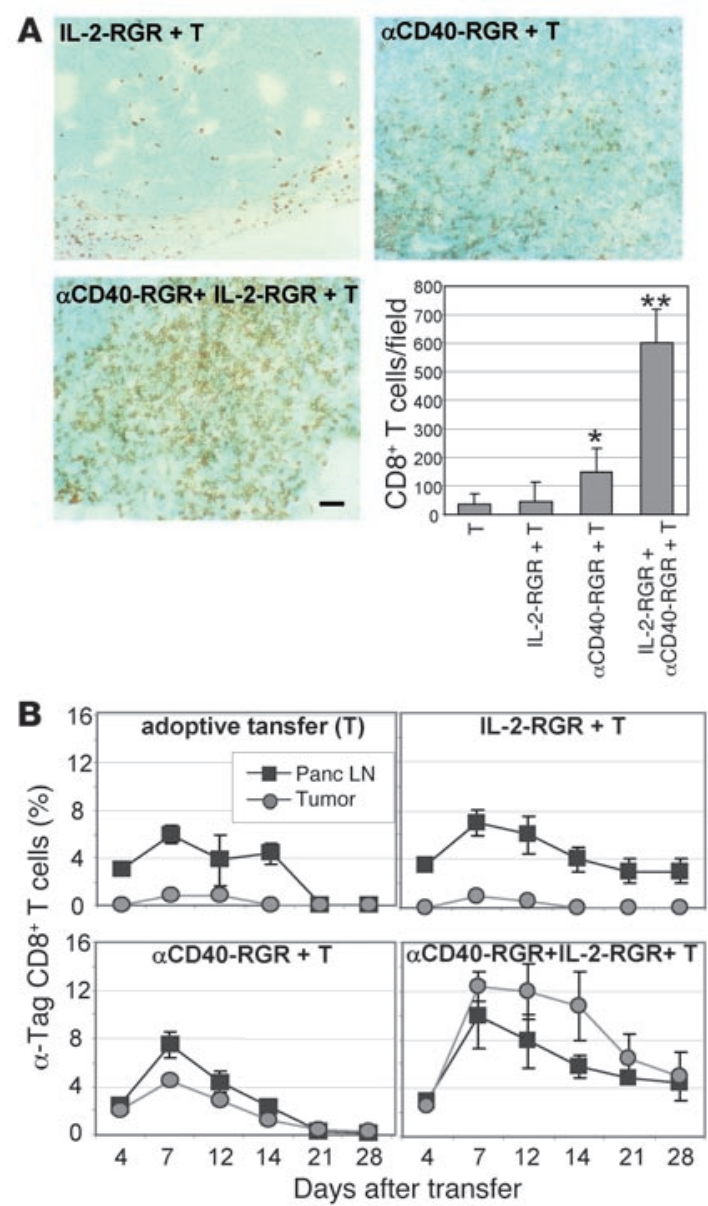

of tumor development and possibly signal strength and use of combination drugs.

Tumor targeted anti-CD40/IL-2 and adoptive immunotherapy: new insights. While intratumoral anti-CD40/IL-2 has considerable impact on the life expectancy of transgenic mice, it merely delays tumor growth. Chronic treatment over at least 5 weeks causes vessel death but fails to activate an effective antitumor immune response. When intratumoral anti-CD40/IL-2 is combined with adoptive transfers of activated antitumor effector cells, $\mathrm{CD} 40^{+}$ tumor endothelia again play an important role, but most likely by increasing the potential of effector cells to reach the tumor site. We show here that intratumoral CD40 stimulation activates blood vessels at the time of $\mathrm{T}$ cell transfer, which in turn may trigger an inflammatory reaction of the vessel wall $(34,41,42)$ and enable accumulation of preactivated, tumor-specific immune cells in the otherwise inaccessible tumor environment. Indeed, local anti-CD40 monotherapy plus adoptive transfers has some beneficial effects on overall survival. This is consistent with a recent report showing that anti-CD40 treatment enhances tumor infiltration by adoptively transferred anti-Tag TCR CD8 ${ }^{+} \mathrm{T}$ cells in a C57BL/6 insulinoma model (43). However effector cells are rapidly cleared, thus limiting therapeutic success. Importantly, we demonstrate here that IL-2 is required to promote persistence of immune effector cells within tumor parenchyma. This accumulation and survival of immune cells is critical for the elimination of cancer cells.

\section{Figure 6}

$\mathrm{T}$ cell accumulation in tumors is promoted by intratumoral anti-CD40/ IL-2 treatment. (A) Immunohistochemical analysis depicting RIP1Tag5 tumor-infiltrating CD8 ${ }^{+} T$ cells 7 days after adoptive transfer. Prior to adoptive transfer mice were treated for 3 weeks with IL-2-RGR, anti-CD40-RGR, or a combination of anti-CD40-RGR/IL-2-RGR as shown in Figure 2A. Original magnification, $\times 10$. Scale bars: $100 \mu \mathrm{m}$. Quantification of CD8+ lymphocytic infiltration after various treatment regimens ( $n=8 ; 5$ microscopic fields per tumor). T, adoptive transfer. ${ }^{*} P=0.005,{ }^{* *} P<0.0001$ compared with adoptive transfer only. (B) The percentage of transferred anti-Tag CD8 ${ }^{+} \mathrm{T}$ cells in pancreatic lymph nodes (panc LN) or RIP1-Tag5 tumors over time was tracked by FACS analysis after 1 adoptive transfer $(T)$ in untreated mice, after IL-2-RGR, anti-CD40-RGR, or anti-CD40-RGR/IL-2-RGR treatment (3-week pretreatment before adoptive transfer) $(n=3)$.

Our findings strongly support a new and highly effective, synergistic, angio-immunotherapeutic approach, where local effects of antiCD40 antibody plus IL-2 "condition" the tumor environment and are further enhanced when combined with adoptive cell transfers.

\section{Methods}

Mice. RIP1-Tag5 transgenic mice (kindly provided by D. Hanahan, UCSF, San Francisco, California, USA) were used on a C3HebFe background. RIP1Tag5 are not tolerant towards Tag due to late onset of transgene expression in adult mice. RIP1-Tag5 mice express Tag at around week 8-10, hyperplastic islets arise at around week 14-16, first abnormal vessels develop in angiogenic islets around week 16, and solid tumors form from week 22 on, followed by premature death at week 30 (29). For adoptive transfer experiments, mice transgenic for a TCR that recognizes Tag presented by the MHC class I molecule $\mathrm{H}-2 \mathrm{~K}^{\mathrm{k}}$ (referred to as TagTCR8; kindly provided by T. Geiger, St. Jude Children's Research Hospital, Memphis, Tennessee, USA and R. Flavell, Yale University, New Haven, Connecticut, USA) (27) or the MHC class II molecule I-A (TagTCR1; kindly provided by I. Foerster, University of Düsseldorf, Düsseldorf, Germany) (28) were used on a C3H background. For bone marrow chimeras, $\mathrm{CD} 40^{-/-}$mice (44) were backcrossed on a $\mathrm{C} 3 \mathrm{H}$ background for at least 5 generations. Lethally irradiated 6-week-old RIP1-Tag5 mice were reconstituted with bone marrow from $\mathrm{CD}^{4-/-}$ mice, or 6-week-old RIP1-Tag5 $\times \mathrm{CD} 40^{-/}$mice (prior to onset of tumor formation) were reconstituted with bone marrow from $\mathrm{CD}_{4} \mathrm{O}^{+/+}(\mathrm{C} 3 \mathrm{H})$ mice. Absence/ presence of $\mathrm{CD} 40$ on spleen cells of $\mathrm{CD} 40^{-/}$chimeras was confirmed 8 weeks after bone marrow reconstitution (data not shown). All mice were kept under specific pathogen-free conditions at the German Cancer Research Center or the University of Western Australia. All experimental protocols were approved by the Animal Welfare Board of the Regierungspräsidium (Karlsruhe, Germany) or the Animal Ethics Committee of the University of Western Australia, Perth, Western Australia, Australia).

Production of RGR-conjugated anti-CD40 antibodies and western blot analysis. Rat monoclonal antibody FGK45 (anti-mouse CD40; isotype IgG1 kappa, ref. 45; a generous gift from K. Melief, University of Leiden, Leiden, The Netherlands) was produced in a miniPERM bioreactor and purified over a goat anti-rat IgG Sepharose CL-4B column. Purified immunoglobulin was dialyzed against PBS and adjusted to a protein concentration of $2 \mathrm{mg} / \mathrm{ml}$. The following peptides (synthesized by Peptide Speciality Laboratories) were conjugated to purified monoclonal anti-CD40 antibodies: RGR, CGGGGGRGRRST-NH $\mathrm{N}_{2}$; and myc-RGR, CGGGEQKLISEEDLGGGRGRRST-NH 2 . For conjugation, the instructions of the Controlled Protein-Protein Cross-linking Kit (Pierce) were followed with minor modifications. A 5-fold molar excess of cross-linking agent Sulfo-SMCC (sulfosuccinimidyl 4-[N-maleimidomethyl] cyclohexane- 1 carboxylate) was added to the antibody that resulted in 1-3 moles of maleimide per mole of antibody. After incubation for 30 minutes at room 
temperature, nonreacted cross-linker was removed by dialysis against PBS. Equal molar amounts of maleimide-activated antibody were mixed with sulfhydryl-containing peptide RGR for 60 minutes at room temperature. Nonbound peptide was removed by dialysis against PBS. Two micrograms of anti-CD40 or anti-CD40-RGR antibodies were separated by $7.5 \%$ nonreducing SDS/PAGE, and the membrane was probed with $0.5 \mu \mathrm{g} / \mathrm{ml}$ biotinylated anti-myc antibodies (Myc1-9E10; ref. 46) and $10 \mathrm{ng} / \mathrm{ml}$ streptavidin-HRP (Vector/Alexis Biochemicals). The same membrane was reprobed with 10 $\mathrm{ng} / \mathrm{ml}$ horse anti-rat IgG-HRP (Vector).

Production of recombinant murine IL-2-RGR fusion protein and assessment of bioactivity. Mature murine IL-2 or IL-2 with a C-terminal modified RGR peptide (CRGRRSTG) were PCR amplified using the following primers $\left(5^{\prime}-3^{\prime}\right)$ : SmaI-IL-2 (GCCCCGGGCGCACCCACTTCAAGCTCCACT) and XhoI-IL-2 (GCCTCGAGGAGGTACATAGTTATTGAGGG) or SmaI-IL-2 and XhoI-IL-2-RGR (GCCTCGAGTCAACCAGTAGAACGACGACCACGACAACCACCACCTTGAGGGCTTGTTGAGATGATG), respectively. Amplified products were cloned into Sma1-XhoI sides of pGEX-6P (Amersham Pharmacia) to produce glutathione-S-transferase (GST) fusion products in bacteria as described (47). Briefly, after isopropyl- $\beta$-D-glactopyranoside (IPTG) induction for 2 hours at $37^{\circ} \mathrm{C}$, cultures were centrifuged, resuspended in ice-cold PBS, sonicated, and protein was resolved in $8 \mathrm{M}$ urea solution containing $50 \mathrm{mM}$ Tris- $\mathrm{HCl}$ ( $\mathrm{pH}$ 8.0), $1 \mathrm{mM}$ DTT, and $1 \mathrm{mM}$ EDTA for 1 hour at room temperature. Denatured IL-2 was refolded through a series of dialyses: first, at $4^{\circ} \mathrm{C}$ against $4 \mathrm{M}$ urea solution (twice, 1 hour each time); next, $2 \mathrm{M}$ urea solution (twice, 1 hour each time); and then, $50 \mathrm{mM}$ Tris- $\mathrm{HCl}$ (pH 8.0), $1 \mathrm{mM}$ DTT, 1 mM EDTA (twice, 1 hour each time and once overnight). Solubilized GST-IL-2/IL-2-RGR proteins were purified using a GSTrap FF column according to the manufacture's instructions (Pharmacia), and the GST tags were removed by PreScission protease cleavage (Pharmacia). Recombinant IL-2 was purchased from R\&D Systems. IL-2-dependent cytotoxic CTL.L2 T cells were resuspended in RPMI1640 medium, supplemented with $2 \mathrm{mM}$ glutamine, $100 \mathrm{U} / \mathrm{ml}$ penicillin and $100 \mu \mathrm{g} / \mathrm{ml}$ streptomycin, $0.05 \mathrm{mM} 2$-mercaptoethanol, and $5 \%$ fetal calf serum. On round bottom microtiter plates, $4 \times 10^{3}$ cells in 0.1 $\mathrm{ml}$ were seeded. Each well received $0.1 \mathrm{ml}$ of serially diluted recombinant protein, and triplicate cultures were incubated. After 48 hours, $1 \mu \mathrm{Ci}$ of $\left[{ }^{3} \mathrm{H}\right]$ thymidine (Amersham) was added per well. Cultures were harvested 18 hours later on filter pads with a cell harvester (Titertek; Flow Laboratories), and radioactivity was measured in scintillation fluid.

In vivo treatment of tumor-bearing RIP1-Tag5 mice with fusion compounds. Mice at 23 weeks of age were injected i.v. with $100 \mu \mathrm{g}$ of anti-CD40-RGR weekly and/or $25 \mu \mathrm{g}$ IL-2-RGR 3 times per week for a 10-week treatment schedule (Figure $2 \mathrm{~A}$ ). In some experiments, adoptive transfers were given in 3 weekly intervals in addition to anti-CD40-RGR/IL-2-RGR treatment. In vitro proliferation and adoptive transfers are described elsewhere (19). Briefly, TagTCR8 splenocytes or TagTCR1 lymph node cells were activated in vitro for 3 days, with $10 \mathrm{U}$ of rIL-2/ml and $25 \mathrm{mM}$ Tag peptide 362-568 (SEFLIEKRI for TagTCR8 cells) or $25 \mathrm{nM}$ Tag peptide 362-384 (TNRFNDLLDRMDIMFGSTGSADI for TagTCR1 cells). C3H-derived splenocytes were activated with $1 \mu \mathrm{g} / \mathrm{ml}$ ConA (Sigma-Aldrich), and $2.5 \times 10^{6}$ activated $\mathrm{CD}^{+}$and $2.5 \times 10^{6} \mathrm{CD}^{+} \mathrm{T}$ cells were transferred. For $\mathrm{T}$ cell depletion studies, anti-L3T4 (anti CD4 ${ }^{+}$, rat anti-mouse GK1.5 hybridoma) and anti-Lyt.2 (anti-CD8 ${ }^{+}$, rat anti-mouse 53-6.7) antibodies were produced in a miniPERM bioreactor and column purified. Specific antibodies or purified irrelevant rat IgG $(0.5 \mathrm{mg})$ were injected i.p. for 3 consecutive days prior to anti-CD40-RGR/IL-2-RGR treatment (Figure 3D), followed by weekly injections of $1 \mathrm{mg}$ antibodies on day 1, 8, 15, 22, and 29. T cell depletion was monitored by FACS on day 1, 14, and 21 (data not shown).

Assessment of toxicity. Serum alanine aminotransferase activity was determined using bioreaction strips on a Reflovet Plus reader (Roche
Diagnostics). Serum TNF- $\alpha$ concentrations were assayed using an Enzyme-Linked Immunosorbent Assay kit according to the manufacturer's protocol (Bio-Scientific).

Histological analyses. For fluorescence detection, recombinant IL-2 proteins were chemically biotinylated with sulfosuccinimidyl-6(biotinamido)hexanoate (EZ-Link sulfo-NHS-LC-Biotin; Pierce) in 0.150 $\mathrm{M} \mathrm{NaCl}$ and $0.1 \mathrm{M}$ phosphate buffer, $\mathrm{pH} 7.2$, following the manufacturer's instructions. Free sulfo-NHS-LC-Biotin was removed by dialysis. Mice were injected i.v. with $100 \mu \mathrm{g}$ anti-CD40-mycRGR or biotinylated IL-2RGR. After 5 minutes of circulation, mice were sacrificed and organs embedded in OCT compound (Tissue Tek) or, alternatively, hearts of mice were perfused with $4 \%$ paraformaldehyde in PBS and embedded in OCT, and $10 \mu \mathrm{m}$ sections were stained with anti-myc antibodies and the Mouse on Mouse (M.O.M.; Vector) kit detection. Biotinylated IL-2 was detected using streptavidin-FITC (Alexis). Immuohistochemistry was performed as described (29). For lectin perfusion, mice were i.v. injected with $100 \mu \mathrm{g}$ of FITC-labeled tomato lectin (Lycopersion esculentum; Vector). After 3 minutes of circulation, hearts of mice were perfused with $4 \%$ paraformaldehyde in PBS. Organs were postfixed for 2 hours in PFA, 2 hours in 30\% sucrose, and overnight in 10\% sucrose and embedded in OTC. For immunohistochemistry the following antibodies were used: anti-ICAM (YN1/1.7.4, $10 \mu \mathrm{g} / \mathrm{ml}$; ATCC), anti-VCAM (42, $10 \mu \mathrm{g} / \mathrm{ml}$; BD Pharmingen), E-selectin (UZ4, $10 \mu \mathrm{g} / \mathrm{ml}$; BD Pharmingen), antiCD4 (GK1.5, $10 \mu \mathrm{g} / \mathrm{ml}$; BD Pharmingen), anti-CD8 (Ly-2, $10 \mu \mathrm{g} / \mathrm{ml}$; BD Pharmingen), anti-CD45 (30-F11, $10 \mu \mathrm{g} / \mathrm{ml}$; BD Pharmingen), antiCD40 (rabbit polyclonal, C-20, $20 \mu \mathrm{g} / \mathrm{ml}$; Santa Cruz Biotechnology Inc.), anti-CD31 (Mec 13.3, $10 \mu \mathrm{g} / \mathrm{ml}$; BD Pharmingen), and anti-Tag (rabbit polyclonal, 1:1000; a generous gift from D. Hanahan). For secondary detection, the following antibodies were used at $3 \mu \mathrm{g} / \mathrm{ml}$ : anti-rat biotin or anti-rabbit biotin followed by ABC elite kit (Vector), cyanin-3-FITC conjugated $\operatorname{IgG~F}\left(\mathrm{ab}^{\prime}\right) 2$ fragment goat anti-rat (Dianova), and cyanin-3conjugated donkey anti-goat IgG (Dianova). The hypoxyprobe-1 kit (Chemicon) was used to detect hypoxia. Hypoxic tumor area was quantified throughout tumors on sections that were $100 \mu \mathrm{m}$ apart. Tumor sections were evaluated for $\mathrm{CD} 8{ }^{+}$lymphocytic infiltration or $\mathrm{CD} 31^{+}$vessels by using a $20 \times$ objective lens, and 5 independent areas were selected, digitally photographed, and counted (ImagePro).

Flow cytometry. Lymph node or tumor cell suspensions were stained with biotinylated anti-mouse V $\beta 8.1$ and $8.2(2 \mu \mathrm{g} / \mathrm{ml}$, clone MR5.2; BD Pharmingen), followed by streptavidin-Red670 (1.7 $\mu \mathrm{g} / \mathrm{ml}$; Life Technologies) and phycoerytrin-conjugated anti-CD $8(2 \mu \mathrm{g} / \mathrm{ml}$, Ly-2; BD Pharmingen) for 2-color analysis. Spleen cells were stained with antibodies against MHC class II (H-2K $\left.\mathrm{K}^{\mathrm{k}}, 11.4 .1,5 \mu \mathrm{g} / \mathrm{ml}\right)$ and CD11c $(2 \mu \mathrm{g} / \mathrm{ml}, \mathrm{HL} 3$; BD Pharmingen). Cells were analyzed on a FACSCalibur (Becton Dickinson).

Statistics. Cumulative survival time was calculated by the Kaplan-Meier method and analyzed by the log-rank test. Student's $t$ test (2-tailed) was used unless indicated otherwise. A $P$ value of less than 0.05 was considered statistically significant. Error bars indicate SD.

\section{Acknowledgments}

We thank Ludmila Umansky and Alexandra Klevenz for excellent technical assistance and R. Flavell, I. Förster, T. Geiger, D. Hanahan, and K. Melief for providing material used in this study. We are also grateful to J. Joyce for advise regarding the RGR peptide and $\mathrm{H}$. Ee for critical reading of the manuscript. This work was supported by grants from the Ada Bartholomew Medical Research Trust, the Cancer Council Western Australia, the Deutsche Forschungsgemeinschaft (SFB405), and by start-up funds to R. Ganss from the Western Australian Institute for Medical Research and the University of Western Australia. 
Received for publication July 5, 2007, and accepted in revised form February 20, 2008.

Address correspondence to: Ruth Ganss, Western Australian Institute for Medical Research, Rear, 50 Murray St., Perth, Western

1. Wu, A.M., and Senter, P.D. 2005. Arming antibodies: prospects and challenges for immunoconjugates. Nat. Biotechnol. 23:1137-1146.

2. Neri, D., and Bicknell, R. 2005. Tumour vascular targeting. Nat. Rev. Cancer. 5:436-446.

3. Ryschich, E., Schmidt, J., Hammerling, G.J., Klar, E., and Ganss, R. 2002. Transformation of the microvascular system during multistage tumorigenesis. Int. J. Cancer. 97:719-725.

4. Joyce, J.A., et al. 2003. Stage-specific vascular markers revealed by phage display in a mouse model of pancreatic islet tumorigenesis. Cancer Cell. 4:393-403.

5. Hanahan, D. 1985. Heritable formation of pancreatic beta-cell tumours in transgenic mice expressing recombinant insulin/simian virus 40 oncogenes. Nature. 315:115-122.

6. Diehl, L., et al. 1999. CD40 activation in vivo overcomes peptide-induced peripheral cytotoxic Tlymphocyte tolerance and augments anti-tumor vaccine efficacy. Nat. Med. 5:774-779.

7. Sotomayor, E.M., et al. 1999. Conversion of tumor-specific CD4+ T-cell tolerance to T-cell priming through in vivo ligation of CD40. Nat. Med. 5:780-787.

8. Nguyen, L.T., et al. 2002. Tumor growth enhances cross-presentation leading to limited $\mathrm{T}$ cell activation without tolerance. J. Exp. Med. 195:423-435.

9. French, R.R., Chan, H.T., Tutt, A.L., and Glennie, M.J. 1999. CD40 antibody evokes a cytotoxic T-cell response that eradicates lymphoma and bypasses T-cell help. Nat. Med. 5:548-553.

10. Todryk, S.M., et al. 2001. CD40 ligation for immunotherapy of solid tumours. J. Immunol. Methods. 248:139-147.

11. van Mierlo, G.J., et al. 2002. CD40 stimulation leads to effective therapy of CD40(-) tumors through induction of strong systemic cytotoxic T lymphocyte immunity. Proc. Natl. Acad. Sci. U. S. A. 99:5561-5566.

12. Cella, M., et al. 1996. Ligation of CD40 on dendritic cells triggers production of high levels of interleukin-12 and enhances T cell stimulatory capacity: T-T help via APC activation. J. Exp. Med. 184:747-752.

13. Schoenberger, S.P., Toes, R.E., van der Voort, E.I, Offringa, R., and Melief, C.J. 1998. T-cell help for cytotoxic T lymphocytes is mediated by CD40CD40L interactions. Nature. 393:480-483.

14. Bennett, S.R., et al. 1998. Help for cytotoxic-T-cell responses is mediated by CD40 signalling. Nature. 393:478-480.

15. Jackaman, C., et al. 2003. IL-2 intratumoral immunotherapy enhances CD8+ T cells that mediate destruction of tumor cells and tumor-associated vasculature: a novel mechanism for IL-2. J. Immunol. 171:5051-5063.

16. Murphy, W.J., et al. 2003. Synergistic anti-tumor responses after administration of agonistic antibodies to CD40 and IL-2: coordination of dendritic and CD8+ cell responses. J. Immunol. 170:2727-2733.
17. McDermott, D.F., and Atkins, M.B. 2004. Application of IL-2 and other cytokines in renal cancer. Expert Opin. Biol. Ther. 4:455-468.

18. Vonderheide, R.H., et al. 2007. Clinical activity and immune modulation in cancer patients treated with CP-870,893, a novel CD40 agonist monoclonal antibody. J. Clin. Oncol. 25:876-883.

19. Garbi, N., Arnold, B., Gordon, S., Hammerling, G.J., and Ganss, R. 2004. CPG motifs as proinflammatory factors render autochthonous tumors permissive for infiltration and destruction. J. Immunol. 172:5861-5869.

20. Berger, M., Bergers, G., Arnold, B., Hammerling, G.J., and Ganss, R. 2005. Regulator of G-protein signaling- 5 induction in pericytes coincides with active vessel remodeling during neovascularization. Blood. 105:1094-1101.

21. Kimura, K., et al. 2006. Pathogenic role of B cells in anti-CD40-induced necroinflammatory liver disease. Am. J. Pathol. 168:786-795.

22. Yellin, M.J., et al. 1995. Ligation of CD40 on fibroblasts induces CD54 (ICAM-1) and CD106 (VCAM-1) up-regulation and IL-6 production and proliferation. J. Leukoc. Biol. 58:209-216.

23. Yellin, M.J., et al. 1995. Functional interactions of T cells with endothelial cells: the role of CD40L-CD40mediated signals. J. Exp. Med. 182:1857-1864.

24. Hollenbaugh, D., et al. 1995. Expression of functional CD40 by vascular endothelial cells. J. Exp. Med. 182:33-40.

25. Chiodoni, C., et al. 2006. Triggering CD40 on endothelial cells contributes to tumor growth. J. Exp. Med. 203:2441-2450.

26. Skowronski, J., Jolicoeur, C., Alpert, S., and Hanahan, D. 1990. Determinants of the B-cell response against a transgenic autoantigen. Proc. Natl. Acad. Sci. U. S. A. 87:7487-7491.

27. Geiger, T., Gooding, L.R., and Flavell, R.A. 1992. $\mathrm{T}$-cell responsiveness to an oncogenic peripheral protein and spontaneous autoimmunity in transgenic mice. Proc. Natl. Acad. Sci. U S A. 89:2985-2989.

28. Forster, I., Hirose, R., Arbeit, J.M., Clausen, B.E., and Hanahan, D. 1995. Limited capacity for tolerization of CD4+ $\mathrm{T}$ cells specific for a pancreatic beta cell neo-antigen. Immunity. 2:573-585.

29. Ganss, R., Ryschich, E., Klar, E., Arnold, B., and Hammerling, G.J. 2002. Combination of T-cell therapy and trigger of inflammation induces remodeling of the vasculature and tumor eradication. Cancer Res. 62:1462-1470.

30. Nelson, D., and Ganss, R. 2006. Tumor growth or regression: powered by inflammation. J. Leukoc. Biol. 80:685-690.

31. Ganss, R., Arnold, B., and Hammerling, G.J. 2004. Mini-review: overcoming tumor-intrinsic resistance to immune effector function. Eur. J. Immunol. 34:2635-2641.

32. Hoffman, J.A., et al. 2003. Progressive vascular changes in a transgenic mouse model of squamous cell carcinoma. Cancer Cell. 4:383-391.

33. Seaman, S., et al. 2007. Genes that distinguish physiological and pathological angiogenesis. Cancer Cell. 11:539-554.

34. Henn, V., et al. 1998. CD40 ligand on activated platelets triggers an inflammatory reaction of endothelial cells. Nature. 391:591-594.

35. Berner, V., et al. 2007. IFN-gamma mediates CD4(+) T-cell loss and impairs secondary antitumor responses after successful initial immunotherapy. Nat. Med. 13:354-360.

36. Welniak, L.A., et al. 2004. Tumor regression by antiCD40 and interleukin-2: role of CD40 in hematopoietic cells and organ-specific effects. Biol. Blood Marrow Transplant. 10:534-539.

37. Baluna, R., Rizo, J., Gordon, B.E., Ghetie, V., and Vitetta, E.S. 1999. Evidence for a structural motif in toxins and interleukin-2 that may be responsible for binding to endothelial cells and initiating vascular leak syndrome. Proc. Natl. Acad. Sci. U. S. A. 96:3957-3962.

38. Ibe, S., Qin, Z., Schuler, T., Preiss, S., and Blankenstein, T. 2001. Tumor rejection by disturbing tumor stroma cell interactions. J. Exp. Med. 194:1549-1559.

39. Carnemolla, B., et al. 2002. Enhancement of the antitumor properties of interleukin- 2 by its targeted delivery to the tumor blood vessel extracellular matrix. Blood. 99:1659-1665.

40. Murugaiyan, G., Martin, S., and Saha, B. 2007. CD40-induced countercurrent conduits for tumor escape or elimination? Trends Immunol. 28:467-473.

41. Dechanet, J., et al. 1997. CD40 ligand stimulates proinflammatory cytokine production by human endothelial cells. J. Immunol. 159:5640-5647.

42. Thienel, U., Loike, J., and Yellin, M.J. 1999. CD154 (CD40L) induces human endothelial cell chemokine production and migration of leukocyte subsets. Cell. Immunol. 198:87-95.

43. Otahal, P., Knowles, B.B., Tevethia, S.S., and Schell, T.D. 2007. Anti-CD40 conditioning enhances the $\mathrm{T}(\mathrm{CD} 8)$ response to a highly tolerogenic epitope and subsequent immunotherapy of simian virus 40 $\mathrm{T}$ antigen-induced pancreatic tumors. J. Immunol. 179:6686-6695

44. Castigli, E., et al. 1994. CD40-deficient mice generated by recombination-activating gene-2-deficient blastocyst complementation. Proc. Natl. Acad. Sci. U. S. A. 91:12135-12139.

45. Rolink, A., Melchers, F., and Andersson, J. 1996. The SCID but not the RAG-2 gene product is required for $\mathrm{S}$ mu-S epsilon heavy chain class switching. Immunity. 5:319-330.

46. Evan, G.I., Lewis, G.K., Ramsay, G., and Bishop, J.M. 1985. Isolation of monoclonal antibodies specific for human c-myc proto-oncogene product. Mol. Cell. Biol. 5:3610-3616.

47. Iwata, H., Yamamoto, M., Hasegawa, A., Kurata, K., and Inoue, T. 2000. Expression of porcine interleukin-2 in Escherichia coli. J. Vet. Med. Sci. 62:1101-1104. 